\title{
Oncofertility in Gynecologic Malignant Tumors
}

\author{
Masataka Adachi, Kouji Banno, Iori Kisu, Megumi Yanokura, Moito Iijima, Takashi Takeda, \\ Kiyoko Umene, Yuya Nogami, Eiichiro Tominaga, Daisuke Aoki
}

Department of Obstetrics and Gynecology, Keio University School of Medicine, Tokyo, Japan

Email:kbanno@z7.keio.jp

Received 15 October 2015; accepted 5 December 2015; published 8 December 2015

Copyright (C) 2015 by authors and Scientific Research Publishing Inc.

This work is licensed under the Creative Commons Attribution International License (CC BY).

http://creativecommons.org/licenses/by/4.0/

(c) (i) Open Access

\begin{abstract}
Long-term survival is the priority in treatment of patients with malignant tumors. In the field of gynecology, fertility preservation has also recently become an important objective due to improved treatment outcomes and different needs of patients. Methods for fertility preservation include cervical conization, ovarian protection against radiation or chemotherapy for ovarian cancer since the ovary is hypersensitive to cancer therapies, treatment of gynecological cancer during pregnancy, and cryopreservation of oocytes, embryos or ovarian tissue before treatment of malignant tumors. Radical trachelectomy for early cervical cancer and treatment with medroxy progesterone acetate for early endometrial carcinoma are also options for fertility preservation, but the efficacy and risk of recurrence have yet to be fully evaluated. The first childbirth following uterine transplantation was also achieved last year and this success has expanded the potential for pregnancy and delivery among cancer survivors.
\end{abstract}

\section{Keywords}

Gynecological Cancer, Fertility Preservation, Cryopreservation, Uterine Transplantation, Pregnancy

\section{Introduction}

As gynecological cancer screening, pap smear and endometrial cytology are performed against cervical cancer and endometrial cancer, respectively. Some women do not access gynecologist until they have symptoms. However, cancer often has already progressed when they recognize symptoms. In the case of ovarian cancer, it lacks symptoms compared with cervical or endometrial cancer because the ovaries are located deep inside the pelvis. In addition, screening methods for ovarian cancer have not been established. Thus, a diagnosis by surgic-

How to cite this paper: Adachi, M., Banno, K., Kisu, I., Yanokura, M., lijima, M., Takeda, T., Umene, K., Nogami, Y., Tominaga, E. and Aoki, D. (2015) Oncofertility in Gynecologic Malignant Tumors. Journal of Cancer Therapy, 6, 1176-1191. 
al removal of the uterus or ovaries is made for most gynecologic tumors. By social background, the onset age of gynecologic cancer has been younger recently. The prognosis for women of reproductive age with malignant tumors has been improved by advances in treatment. However, uterine and ovarian functions are reduced by cancer treatment, resulting in the potential for infertility. Therefore, fertility preservation is a key aspect of QOL after cancer treatment, but appropriate approaches remain uncertain. The American Society of Clinical Oncology (ASCO) recently proposed the first guidelines for fertility preservation in patients with a malignant tumor [1]. In vitro fertilization has solved some problems, but age at pregnancy has also increased due to development of reproductive technology and delayed marriage, as aspects of social advancement of women. Opportunities for diagnosis of gynecological cancer have also become more frequent. Treatment of gynecological cancer complicated with pregnancy involves both maternal and fetal lives, and physicians often recommend prolongation of maternal life and discontinuation of pregnancy based on limited evidence. In 2009, the European Society of Gynecological Oncology developed the first guidelines to establish an international consensus [2]. The current purpose of treatment for a malignant tumor during pregnancy is similar to that in non-pregnant patients, with added fetal protection. However, recent studies have proposed different therapeutic strategies corresponding to gestational age and the clinical stage of the malignant tumor.

\section{High Risk Factors of Gynecologic Malignant Tumors}

Environmental and genetic factor are two major factors involved in the onset of malignant tumors. For environmental factors, exposure to intrinsic or extrinsic carcinogen, such as hormonal abnormalities, infections or drugs are included. In contrast, genetic factor includes abnormalities of cancer-related genes, such as germline mutation of oncogene or tumor suppressor gene.

As environmental factors of gynecologic malignant tumors, human papillomavirus (HPV) infection, smoking and diethylstilbestrol exposure are associated with cervical cancer. Obesity, diabetes mellitus or polycystic ovarian syndrome are involved in endometrial cancer. For ovarian cancer, early menarche, late menopause and nulliparous are high risk factor [3]. Therefore, it is known that childbearing and breastfeeding decrease the risk of ovarian cancer. Furthermore, oral contraceptive pill decreases the risk of endometrial and ovarian cancer [3].

On the other hand, hereditary gynecologic cancers include ovarian cancer, fallopian tube cancer and primary peritoneal cancer associated with hereditary breast and ovarian cancer (HBOC); endometrial and ovarian cancer associated with Lynch syndrome; cervical cancer and ovarian cancer associated with Peutz-Jeghers syndrome; and endometrial cancer associated with Cowden disease. Of these, clinically important and frequent hereditary gynecologic cancers are HBOC and Lynch syndrome [4]. HBOC is an autosomal dominant hereditary disease caused by germline mutation of breast cancer susceptibility (BRCA) 1 and BRCA2 gene. The estimated risks of developing ovarian cancer by the age of 70 years are $35 \%-60 \%$ and $10 \%-27 \%$ in BRCA1 and BRCA2 mutation carriers, respectively [5]. Lynch syndrome is also an autosomal dominant hereditary disease and it is caused by germline mutation of DNA mismatch repair (MMR) genes, which include mutL homolog 1 (MLH1), mutS homolog 2 (MSH2), MSH6 and postmeiotic segregation increased 2 (PMS2) [6]. For patients of Lynch syndrome, the estimated risk of endometrial and ovarian cancer at the age of 70 years are about $60 \%$ and $12 \%$, respectively [5]. Because effectiveness of screening methods against these hereditary gynecologic cancer have not been proved, risk-reducing surgery, which is a prophylactic surgery to remove ovary, fallopian tube or uterus might be performed before the onset of cancer. However, this approach is indicated for women aged 35 - 40 years or upon completion of child bearing [7] [8]. Thus, it is not available to women who wish fertility preservation.

These two factors are related to each other clinically. Thus, early detection or risk management of these gynecologic tumors is sometimes difficult. Moreover, the onset age of gynecologic tumors has decreased and age at childbearing has also increased as mentioned above. Therefore, fertility preservation is becoming important medically and socially.

\section{Fertility Preservation in Treatment of Cervical Cancer}

Fertility is preserved by retention of the ovary or uterus. However, radical hysterectomy is often chosen in treatment of a gynecological malignant tumor since patient survival is the first priority. Thus, all genitalia are resected in curative treatment, resulting in infertility. In addition, since the onset age of cervical cancer has decreased and the childbearing age has increased, fertility preservation in patients with cervical cancer is more 
frequently required. The current standard of care includes surgery and radiotherapy. However, radiation to the pelvis damages ovarian function, and thus surgery is the main option for fertility preservation. For advanced cervical cancer of stage III or higher, concurrent chemoradiotherapy is the main treatment (Figure 1).

Cervical conization is an established therapy for cervical cancer that permits fertility preservation. This procedure is used for stage IA1 cervical cancer with no vascular invasion or lymph node metastasis in patients who wish for fertility preservation. Conical resection of the uterus is performed from the external part toward the cervix using a cold knife or an electric laser scalpel in a loop electrosurgical excision procedure (LEEP). The uterus cannot be preserved if the stump of the removed cervix is not negative. However, postoperative risks for infertility, preterm delivery and abortion remain, although fertility is preserved [9]-[11]. Arbyn et al. conducted a meta-analysis of risks for preterm delivery and perinatal mortality 28 to 34 weeks after conization [12]. Compared to controls, performance of the procedure using a cold knife resulted in significantly higher perinatal mortality ( $4.3 \%$ vs. $0.5 \%)$ and preterm delivery at $32-34$ weeks ( $4.6 \%$ vs. $1.6 \%)$, but not at $28-32$ weeks ( $0.5 \%$ vs. $0.8 \%)$; while LEEP showed no significant differences in perinatal mortality ( $0.6 \%$ vs. $0.5 \%)$ and preterm delivery at 32 - 34 weeks ( $2.0 \%$ vs. $1.4 \%$ ) and 28 - 32 weeks ( $0.5 \%$ vs. $0.8 \%)$. In contrast, in a comparison of 8180 subjects with delivery after LEEP and 544,498 subjects with other delivery, Noehr et al. found that spontaneous preterm delivery was significantly higher in delivery after LEEP throughout gestation (21 - 27 weeks: $0.6 \%$ vs. $0.2 \%$, 28 - 31 weeks: $0.8 \%$ vs. $0.3 \%$, 32 - 36 weeks: $5.0 \%$ vs. $2.9 \%$ ) [13]. Although there are differences between studies, it is apparent that surgery using a cold knife produces a higher risk for preterm delivery, whereas LEEP may increase the risks for preterm delivery and perinatal mortality.

Fertility preservation may also be achieved in radical trachelectomy, which involves dissection of lymph nodes, resection of paracervical connective tissues and basal ligaments with the cervix, and anastomosis of the remaining uterus and vagina to preserve fertility [14]. Radical trachelectomy is applied to cases of stage IA1 with vascular invasion that cannot be treated by cervical conization and to cases of stages IA2 to IB1 [14]. However, similarly to cervical conization, this procedure may increase risks for infertility, preterm delivery and abortion, although fertility is preserved.

After vaginal radical trachelectomy (VRT), Plante et al. found a 70\% - 79\% spontaneous success rate among women attempting to conceive, and the estimated cumulative fertility rate was 55\% [15]. In a comparison of VRT and abdominal radical trachelectomy (ART), Rob et al. found a significantly lower pregnancy rate after ART (48\% vs. $16 \%$ ), with this result concluded to be due to surgical invasion in ART that affected the pelvic environment, i.e., direct and indirect effects on oocytes and implantation [14]. VRT is an innovative procedure that provides fertility preservation for many patients with cervical cancer.

Radiotherapy is the current standard of care for cervical cancer, but has a high risk for ovarian failure. Preventing radiation exposure is required to preserve ovarian function, and ovary shielding and movement during radiation have been examined. In ovary shielding, metal blocks are used to decrease the dose reaching the ovary. In ovary movement, the ovary is positioned away from the radiated position for protection against exposure. Both procedures are described in the ASCO Guidelines as established therapy.

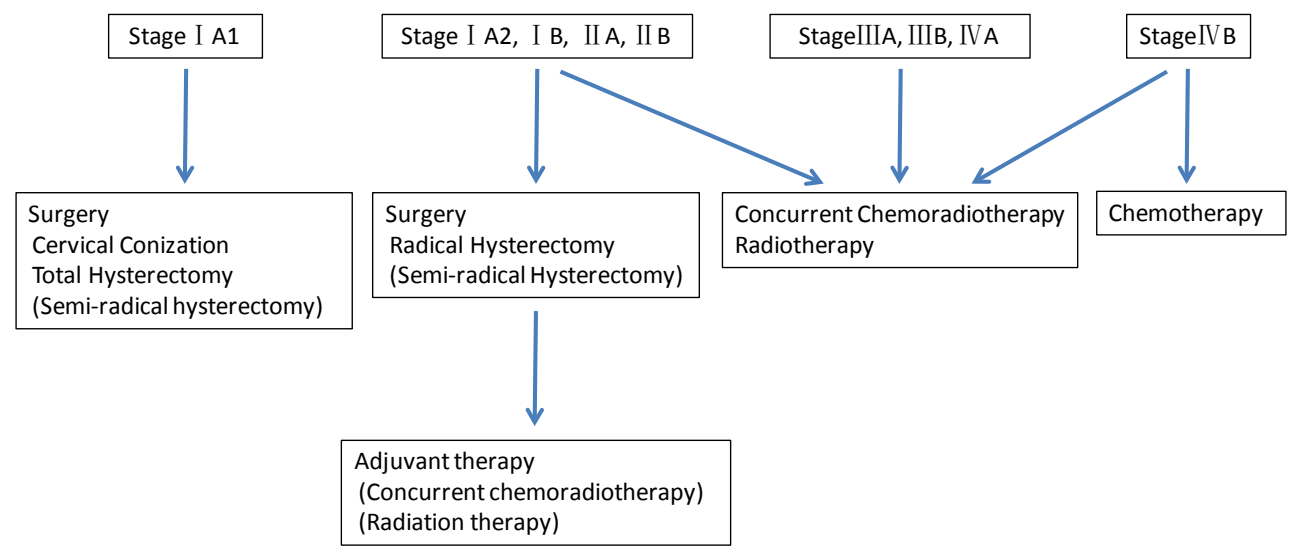

Figure 1. Clinical stage and therapy for cervical cancer. The subjects were classified by FIGO stage (2008). Cervical conization and radical trachelectomy increase risks for infertility, preterm delivery and abortion, but preserve fertility. 


\section{Fertility Preservation in Treatment of Endometrial Cancer}

Endometrial cancer occurs most frequently in women over fifty, but increases in younger patients. The increased number of women who delay childbearing has made fertility preservation more important in treatment of this cancer. Endometrial cancer occurs in the uterine cavity, which contains the placenta and fetus, and this makes it difficult to preserve fertility in surgery. However, well-differentiated adenocarcinoma in younger women is often hormone-dependent and is likely to be responsive to hormone therapy [16]-[22]. Hormone drugs used for endometrial cancer include progestogens such as medroxy progesterone acetate (MPA). Progestin therapy is used for patients with a histological diagnosis of grade 1 endometrioid adenocarcinoma and no muscle invasion or ectopic metastasis. In a systematic review of 2471 patients with advanced or recurrent endometrial cancer treated with hormone drugs in 5 randomized comparative studies and 29 phase II studies, Decruze et al. found an overall response rate to hormone therapy of $11 \%$ to $56 \%$ in previously untreated patients with grade 1 or 2 endometrial cancer and progression-free survival of 2.5 - 14 months [23]. Metformin may decrease the risk for recurrence after MPA treatment, but this treatment is not recommended in the guidelines. Metformin is a type 2 diabetes drug that also inhibits cancer cell growth by AMP-activated protein kinase (AMPK) activation in the mammalian target of rapamycin (mTOR)/S6 kinase (S6K) pathway [24]-[29]. Two retrospective studies have shown improved relapse-free and overall survival in patients treated with metformin [30] [31]. Further studies of treatment with these less invasive drugs may establish procedures for fertility preservation in patients with endometrial cancer.

\section{Fertility Preservation in Treatment of Ovarian Cancer}

Fertility preservation is currently difficult for patients with ovarian cancer. The histological type and advanced stage of ovarian cancer are diagnosed only by resection, and debulking surgery targeting complete remission is strongly recommended [32] [33]. In stage IA grade 1 epithelial ovarian cancer, fertility is preserved by oophorectomy on the affected side and omentectomy [34] [35]. No definite consensus has been established for clear cell carcinoma, even in stage IA, and fertility preservation after treatment was originally thought to be impossible. In a nonrandomized comparative study conducted at 30 sites, fertility preservation was recommended for patients with non-clear cell carcinoma stage IA grade 1/2, but found to depend on the need for postoperative adjuvant chemotherapy in patients with clear cell carcinoma stage IA and non-clear cell carcinoma stage IC grade $1 / 2$ (Table 1) [36].

For a borderline tumor, treatment with fertility preservation is considered for cases in stages I to IV. A large retrospective study in 950 patients with borderline tumors showed that the significant prognostic factors for progression in patients aged $<40$ years were an advanced stage (IIA-C vs. IA/B HR: 3.00, 95\% CI: 1.39, 6.48; IIIA-C vs. IA/B HR: 3.38, 95\% CI: 1.42, 8.09) and fertility preservation [37]. However, the rate of malignant transformation at relapse was $66.7 \%$ in patients aged $\geq 40$ years, but only $12 \%$ in those aged $<40$ (who mainly underwent surgery with fertility preservation), suggesting no change in the 5-year survival rate. The complete response to salvage chemotherapy is high and the prognosis after relapse is good following fertility preservation for a borderline tumor, although the risk for relapse is higher than that in patients without fertility preservation; therefore, fertility preservation is allowable for a borderline tumor [38].

Malignant ovarian germ cell tumor frequently occurs in younger patients and is responsive to chemotherapy, with no significant difference in recurrence and 5-year survival between patients with and without fertility preservation [39]. Therefore, if a patient wishes for fertility preservation, she can choose the treatment option after stage-determining laparotomy and oophorectomy on the affected side and then undergo postoperative chemotherapy for complete cure using BEP therapy with bleomycin, etoposide and cisplatin.

Table 1. Recommendation for fertility-sparing surgery in young patients with ovarian cancer.

\begin{tabular}{cccc}
\hline \multirow{2}{*}{$\begin{array}{c}\text { FIGO Stage } \\
(2008)\end{array}$} & non-CCH or G1, G2 & Histology or Grade & \\
\cline { 2 - 4 } IA & Offer FSS & CCH & non-CCH or G3 \\
IC & Consider FSS + CT & Consider FSS + CT & No FSS \\
\hline
\end{tabular}

CCH: clear cell histology; FSS: fertility-sparing surgery; CT: chemotherapy. 


\section{Pregnancy Complicated with Cervical Cancer}

Cervical cancer associated with pregnancy occurs in $0.02 \%-0.9 \%$ of all pregnant women [40]. It is important to inform patients that treatment of a malignant tumor during pregnancy remains investigational and is based on limited evidence, and then to offer fertility preservation to those who still have a strong desire to remain pregnant. Such patients are generally treated with a standard regimen of chemotherapy and surgery, with contraindication of radiation at therapeutic doses to the abdomen and pelvis due to serious adverse reactions of microcephaly, mental retardation, microphthalmia, cataract, skeletal deformity, and death in the fetus [41].

If microscopic invasion is found in biopsy and colposcopy, diagnostic conization is conducted from weeks 12 to 20 of gestation. Cervical conization is applied for stage IA1 cervical cancer. In patients with stage IA2/IB1 cervical cancer, lymph nodes are dissected by laparoscopy to determine the possibility of preserving a pregnant uterus (Figure 2) [42]-[44]. If the result is positive, pregnancy is discontinued due to the high-risk lesion. Patients in stage IA2 with negative pelvic lymph nodes (PLNs) and those with a stage IB1 tumor of $\leq 2 \mathrm{~cm}$ have options of simple cervical trachelectomy or LEEP during gestation, or standard treatment after birth [14] [45]. Surgery was postponed until after birth in 76 patients with stage IB1 cervical cancer who were negative in laparoscopic PLN dissection, with resulting survival rate of $95 \%$ and no relapse in follow up for 37.5 months [46]. Radical trachelectomy is not recommended for pregnant patients in stage IB1 based on a study showing a preterm delivery rate of $60 \%$ [47]; however, only about 5 subjects were included in this study and the procedure may still be possible. Successful births were reported by Iwami et al. [48] after VRT and by Aoki et al. [49] after ART. Patients with a PLN-negative tumor of $\geq 2 \mathrm{~cm}$ underwent platinum-based chemotherapy as standard treatment after birth [50]. Outcomes in 2014 showed 27-month survival of $70 \%$ and progression-free survival of $58.9 \%$ in 17 stage IB2 patients, and 14-month survival of 70\% in 10 patients in stage III or higher [51]. Stage IB2 or higher is confirmed if dissected para-aortic lymph nodes (PANs) are negative, in addition to PLNs. The therapeutic significance of dissection is unclear, but this information is used to determine the need for termination of pregnancy.

Laparoscopic lymph node dissection can be performed safely in gestational weeks 13 - 20. For a patient di-

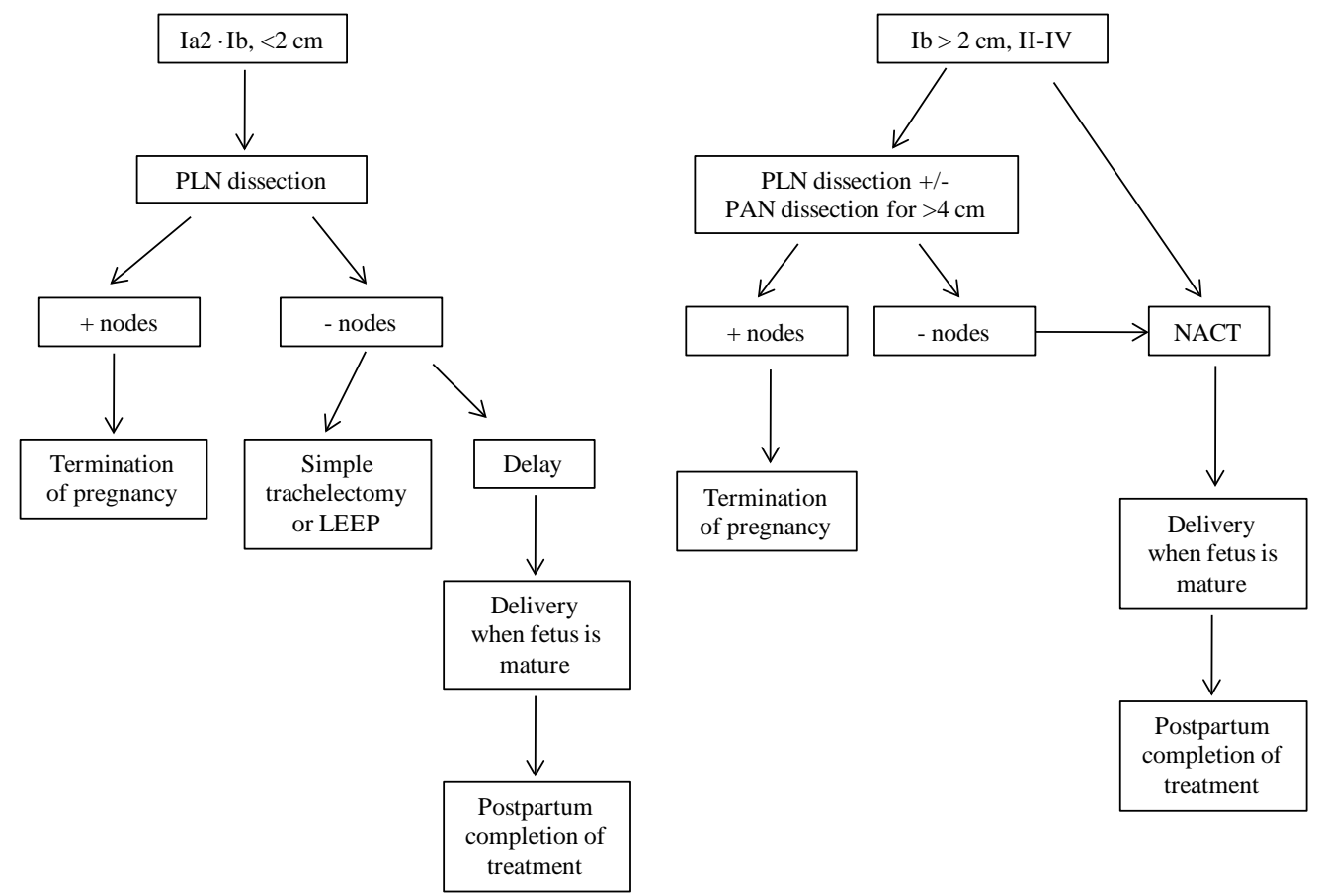

Figure 2. Treatment strategy for cervical cancer in pregnancy (modified from Amant et al. [51]). The subjects were classified by FIGO stage (2008). The treatment algorithm is for cervical cancer diagnosed within 22 - 25 weeks of gestation. PAN dissection is only recommended for tumors of size $4 \mathrm{~cm}$ and larger. PLN: pelvic lymph node, PAN: para-aortic lymph node, LEEP: loop electrosurgical excision procedure, NACT: neoadjuvant chemotherapy. 
agnosed with stage IA2 or IB1 cervical cancer of $\leq 2 \mathrm{~cm}$ at later than 22 - 25 weeks of gestation, this procedure should be postponed until after birth. If cancer progression is found during pregnancy, neoadjuvant chemotherapy (NACT) or preterm delivery is performed. In particular, a patient with a highly advanced cancer requires immediate chemotherapy. The recommended regimen includes cisplatin $\left(75 \mathrm{mg} / \mathrm{m}^{2}\right)$ with tri-weekly paclitaxel $\left(175 \mathrm{mg} / \mathrm{m}^{2}\right)$ [51] [52]. Pharmacokinetic changes including absorption, distribution, metabolism and excretion begin at week 4 of gestation, with increased distribution volume and clearance influencing the plasma drug concentration [53]. However, a large cohort study in 447 pregnant patients with breast cancer showed no significant difference in the outcomes of standard therapy compared to non-pregnant patients [54]. Therefore, the dose should be based on body weight and height during pregnancy.

\section{Pregnancy Complicated by Ovarian Cancer}

Current use of routine ultrasonography during pregnancy frequently leads to detection of an asymptomatic ovarian cyst [55]. An ovarian cyst is detected in $1 \%-4 \%$ of all pregnant women and $90 \%$ of these cysts disappear spontaneously [56]. Complication of ovarian cancer is only found in 1 per 10,000 pregnant women; however, ovarian cancer is the second most common gynecological cancer in pregnancy, after cervical cancer [57]. A benign cyst can be followed up conservatively, but if a cyst is suspected to be malignant, the adnexa is resected for determination of the disease stage. To prevent placental disruption due to decreased hormone levels, bilateral oophorectomy is recommended after 14 - 16 weeks of gestation [51] [58].

The effect of chemotherapy on the fetus depends on the timing, duration, dose and transplacental transfer. Chemotherapy during the second trimester of pregnancy and later has no correlation with increased congenital anomalies [59]. In contrast, chemotherapy during the first trimester until 14 weeks of gestation results in teratogenicity, particularly in weeks 3 - 5 when rapid cell division and differentiation occur during gastrulation. Anthracyclines such as doxorubicin and taxanes such as paclitaxel, which are used for treatment of malignant epithelial tumors, cause intrauterine growth retardation and transient myelosuppression. Therefore, an examination of the neonate at birth is necessary [60]. Adverse events caused by platinum-based drugs, including cisplatin and carboplatin, have not been found, but long-term neurological effects are currently being examined [61]. Anthracyclines have cardiotoxicity, but no fetal toxicity; however, definite evidence is lacking and use of these drugs should be avoided if possible [62] [63]. Gemcitabine, vinorelbine and topotecan are rarely used in pregnant patients and their use in these patients should be avoided [64].

Different kinds of treatment are conducted for early and advanced malignant epithelial tumors. Patients with early invasive cancer of stage IA grade 1 undergo surgery to preserve the uterus and the healthy ovary, similarly to non-pregnant patients, whereas those in stage IA grade 2 - 3, IB, IC and IIA undergo lymph node dissection and chemotherapy with platinum-based drugs [65]. Successful control of early ovarian cancer by robotic surgery was described for the first time in April 2015 [66]. A 14-week pregnant patient with a suspected malignant ovarian cyst underwent unilateral salpingo-oophorectomy with preservation of the fetus and uterus, bilateral pelvic lymph node dissection and omentectomy. After 5 courses of postoperative chemotherapy with carboplatin and paclitaxel, a child was delivered by Cesarean section at week 37. There was no postoperative recurrence during 18-month follow up.

Artificial abortion is the preferred approach for pregnant patients with advanced malignant epithelial tumor because it is difficult to resect a large lesion [67]. However, a patient who desires to be pregnant can receive NACT until birth and undergo resection after birth [68] [69]. Chemotherapy using a standard regimen of paclitaxel and carboplatin is recommended [70]. Bevacizumab, an angiogenesis inhibitor, is also of interest as immunoglobulin therapy for ovarian cancer, but adverse events including fetal death have been found in animals. Therefore, bevacizumab should not be administered to pregnant patients [71]. If a borderline tumor is suspected, staging surgery including unilateral salpingo-oophorectomy, omentectomy, appendectomy and intraabdominal biopsy is conducted. A recent study showed that $20 \%$ of patients were in FIGO Stage II/III based on the final pathologic diagnosis, but none developed advanced invasive cancer [69]. Since examinations of the pelvic peritoneum and Douglas' pouch are difficult for pregnant patients, it is recommended that salpingo-oophorectomy should be conducted before birth and staging surgery should be performed again after birth.

Germ cell and sex cord-stromal tumors are typically found at stage I because these are prevalent at a young reproductive age and are detected by ultrasonography early, with subsequent treatment by surgery and NACT [69]. Treatment depends on the histological type, but all regimens include platinum-based drugs. Non-pregnant patients commonly receive BEP therapy with bleomycin, etoposide and cisplatin, whereas paclitaxel-carboplatin 
or cisplatin-vinblastine-bleomycin is used in pregnant patients. Cisplatin is used more frequently than carboplatin because of a lower incidence of thrombocytopenia and placental transfer [72]. Paclitaxel is effective for germ cell tumors and vinca alkaloids are classical anticancer drugs that can be used safely in pregnant women [73].

\section{Preservation of Ovarian Function in Treatment of Malignant Tumors}

Procedures for preservation of ovarian function in radiotherapy and chemotherapy for malignant tumors may be conducted concomitantly or in advance. One such procedure involves use of a gonadotropin-releasing hormone $(\mathrm{GnRH})$ analog as a synthetic hormone to reduce lesions in endometriosis and uterine fibroids. Initial studies in monkeys showed that the GnRH analog had a preventive effect on ovarian toxicity caused by cyclophosphamide [74]. Blumenfeld et al. found that GnRH protected the ovary during chemotherapy in patients aged 14 to 40 with malignant lymphoma and leukemia, with a rate of premature ovarian failure of $2 \%$ in 44 subjects treated with chemotherapy and GnRH that was significantly lower than that of $60 \%$ in 55 subjects treated with chemotherapy alone [75]. In a meta-analysis of 12 studies (579 subjects), Beck-Fruchter et al. found incidences of premature ovarian failure of $9 \%$ in combination chemotherapy and 59\% with chemotherapy alone [76]. However, other meta-analyses and prospective studies of GnRH analogs have found negative results for ovary protection [77]. Therefore, the evidence for the efficacy of this approach remains limited.

Other procedures for preserving fertility of cancer patients include freezing of embryos, unfertilized oocytes and ovarian tissue. Embryo cryopreservation is an established technique that is recommended by the ASCO. It has the advantage of a high pregnancy rate after transplantation because it is already established as a general infertility treatment. One disadvantage is that the procedure takes approximately 2 to 4 weeks after menstruation, and this may compromise the need for immediate chemotherapy for the primary disease. This procedure is also applicable only for married persons, and may result in a decrease in oocytes immediately after chemotherapy and have risks for drug-induced congenital anomalies [78] [79].

Compared to embryo cryopreservation, cryopreservation of oocytes is used in more patients and is superior in that it is applicable for all women with menstruation. However, the procedure takes a long time, similarly to embryo cryopreservation, and the fertility and production rates are lower than those in embryo preservation. It is often difficult to cryopreserve many unfertilized oocytes because the oocytes must be cryopreserved in a short time before anticancer therapy and after definitive diagnosis. Goldman et al. evaluated cryopreserved oocytes from 2004 to 2009 and reported that oocyte survival rate, 2PN fertilization rate and live birth rate per mature oocyte retrieved (LBR-MOR) were $82.5 \%, 81 \%$ and $2.7 \%$, respectively [80].

Cryopreservation of ovarian tissue is under development as an investigational therapy. Oktay et al. applied this procedure to humans in 1999 [81] and the first birth occurred in 2004 [82]. At least 35 newborns have been produced up to June 2015 [83]. Embryos and unfertilized oocytes in only one cycle before treatment are cryopreserved, and thus the number of embryos or oocytes is insufficient for fertility preservation for a lifetime. On the other hand, many oocytes can be preserved as primary follicles using this procedure. Since drawing of oocytes is not required, cryopreservation of ovarian tissue is applicable for children before menarche. In June 2015, the first birth using an ovary cryopreserved before menarche was reported in Belgium [83]. However, cancer cells may be contained in the ovary, and these cells can be imported into the body by thawing and transplantation of ovarian tissue after remission of the primary disease. A study in mice showed recurrence of malignant lymphoma via a transplanted ovary [84]. Therefore, autografting does not reduce the risk to zero, but the risk for malignant cell retransplantation depends on the primary disease. Dolmans et al. found that this risk was high in patients with leukemia and relatively low in those with malignant lymphoma, cervical cancer and Ewing's sarcoma [84]. However, adenocarcinoma is currently increasing and now accounts for $20 \%$ of cases of cervical cancer [85]. Furthermore, adenocarcinoma metastasizes to the ovary more frequently than squamous cell carcinoma [86] and ovary cryopreservation is not recommended in patients with cancer that has a tendency for ovary metastasis [87]. Therefore, there is a need to examine this method by comparing different tissue types. The ideal procedure for avoiding the risk for malignant cell retransplantation is to establish xenotransplantation or an in vitro culture system using isolated ovarian tissue and immature follicles. However, currently there are few centers for ovary cryopreservation in Japan and the number of subjects is too low to evaluate the prognosis. Table 2 illustrate and summarize current used methods of fertility preservation in treatment of malignant tumors [88].

\section{Uterine Transplantation}

Uterine transplantation is an innovative option for a woman who has lost her uterus due to cancer treatment to 
Table 2. Current used methods of fertility preservation in treatment of malignant tumors (modified and arranged from Tomao et al. [88]).

\begin{tabular}{llll}
\hline Methods & Indication & Advantages & Risks and Limitations \\
\hline Cervical conization & $\begin{array}{l}\text {-Stage IA cervical cancer } \\
\text { without vascular invasion or } \\
\text { lymph node metastasis }\end{array}$ & -Fertility is preserved & $\begin{array}{l}\text {-Preterm delivery or abortion still } \\
\text { remain }\end{array}$
\end{tabular}

Radical trachelectomy

Ovarian protection against radiotherapy

Medroxyproge-sterone acetate (MPA) therapy

Unilateral salpingo-oophorectomy of the affected side + omentectomy, peritoneal sampling

Gonadotropin-releasing hormone $(\mathrm{GnRH})$ analog

Freezing of unfertilized oocytes

Freezing of embryo

Freezing of ovarian tissue pediatric cancers, such as leukemia, lymphoma -Procedure is performed before cancer treatment
-Mainly advanced cervical cancer of stage III or higher

-Grade 1 endometrioid adenocarcinoma without muscle invasion or ectopic metastasis cancer treatment
-Feasibility of treatment

-Good tolerability

$-11 \%-56 \%$ of response rate
-Stage IA epithelial ovarian cancer with histology of non-clear -Preservation of the uterus cell and grade $1 / 2$

-All stages of borderline tumor -All stages of malignant ovarian germ cell tumor

-Various kinds of tumors -It is concomitantly administered while undergoing radiotherapy or chemotherapy

-Various kinds of tumors -Procedure is performed before

-Various kinds of tumors -Procedure is performed before cancer treatment -High pregnancy rate than and contralateral ovary with fertility maintenance -Usually good prognosis

-Preventive effect on ovarian toxicity caused by chemotherapy or radiotherapy

-Applicable for all women with menstruation

\section{-Established technique as} general infertility treatment freezing of unfertilized oocyte

-Applicable even for women before menarche -Ovarian stimulation is unnecessary -Many oocytes can be preserved at once -Immediate treatment for the

primary disease is possible

-Possibilities of conversion to radical hysterectomy

-Preterm delivery or abortion still remain

-Artificial reproductive technology is needed in some cases

-Sometimes oocyte retrieval is difficult for the cases of ovaries movement

-Frequent follow-up is necessary while treatment

-Side effect (liver toxicity,

hypercoagulopathy, etc.)

-Possibilities of recurrence

-Fertility is not preserved when cancer has progressed

-Risk of progression in case of inadequate staging

-High rate of malignant transformation at relapse in patients aged $\geq 40$ years

for borderline tumor

-Chemotherapy (BEP) remains a contentious issue over concerns about fertility and late side effect of treatment

-Evidence of the efficacy is limited and is still controversial

-Takes at least several weeks after menstruation for oocyte retrieval -Ovarian stimulation is necessary -Compromise the need for immediate chemotherapy for the primary disease -Low pregnancy rate

-Takes at least several weeks after menstruation for oocyte retrieval -Ovarian stimulation is necessary -Compromise the need for immediate chemotherapy for the primary disease -Applicable only for married couple

-Risk of reintroducing malignant cells when cryopreserved ovarian tissue is autotransplanted after cancer treatment -Still investigational level

deliver her child from a transplanted uterus. Uterine transplantation allows a recipient to become pregnant with the donor uterus and deliver a child from this uterus (Figure 3). The first uterine transplantation in humans was performed in 2000, but failed because of uterus necrosis due to intravascular thrombosis 99 days after transplantation [89]. However, pregnancy after transplantation with a uterus from a brain-dead donor was achieved in Turkey in 2011 [90] and delivery by a patient who underwent uterine transplantation in Sweden was reported in 


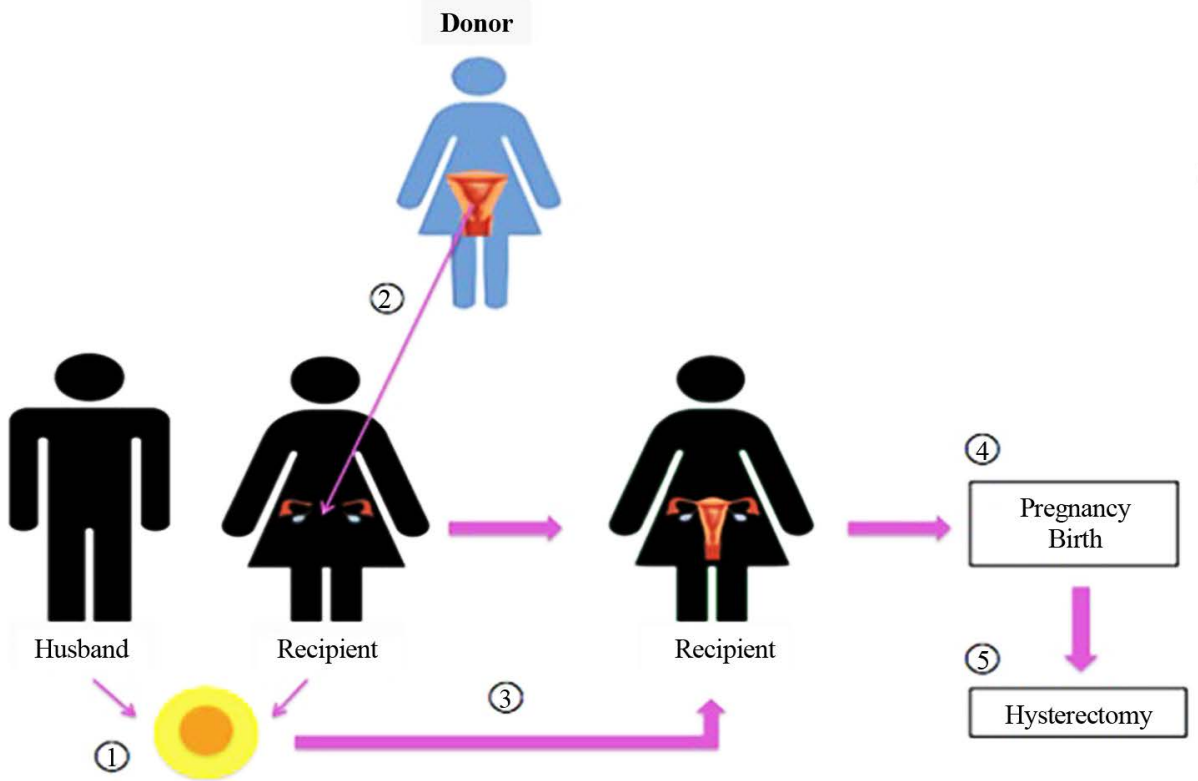

Figure 3. Procedure for uterine transplantation. Fertilized oocytes of the recipient couple are cryopreserved in advance and the donor uterus is transplanted to the recipient. If the uterine graft is alive, the fertilized oocytes are then returned to the uterus, and pregnancy and birth are awaited. Since the uterus is removed after birth, immunosuppressants are not administered inical stage and therapy for cervical cancer.

2014 [91], leading to potential use of uterine transplantation worldwide.

In Sweden, Mats et al. described 9 uterus transplantations in 8 patients with Rokitansky syndrome and 1 patient who had undergone hysterectomy for cervical cancer. The mean age of the recipients was 31 years old and that of the donors was 53 years old (4 premenopausal and 5 postmenopausal women) [92]. The donor's uterine artery or vein was anastomosed to the recipient's external iliac artery/vein. Mycophenolate mofetil (MMF) was administered as preoperative immunosuppressant; methylprednisolone, antithymocyte antibody and thymoglobulin were given as intraoperative immunosuppressants; and tacrolimus, prednisolone and MMF were used as postoperative immunosuppressants. No major postoperative complications occurred. At six months post-transplant, 7 uteri were functional and menstruation was confirmed, but 2 uteri had been removed due to thrombosis in the bilateral uterine arteries and intrauterine infection, respectively. The patient with thrombosis had a history of protein C deficiency, i.e., thrombotic predisposition. A 35-year-old woman with Rokitansky syndrome who received a transplanted uterus from her friend, a 61-year-old postmenopausal woman, gave birth in October 2014. Tacrolimus and MMF were administered as immunosuppressants to prevent graft-versus-host disease and the patient became pregnant with one embryo transplantation. The patient gave birth by Cesarean section in week 31 of gestation due to pregnancy-induced hypertension, but both mother and child had no abnormal findings and were doing well at the time of the report [91].

Based on the above, uterus transplantation may be a new option for women with uterine factor infertility. However, there is a concern that patients with cervical cancer who undergo transplantation may have recurrent cancer. The incidence of malignant tumor in organ transplant recipients is higher than that in the general population, and malignant tumor caused by viral infection is particularly associated with use of immunosuppressants [93]. Patients with cervical cancer have increased morbidities of human papillomavirus (HPV) infection and cervical tumors [94]. Therefore, uterine transplantation in patients with cervical cancer may enhance viral reactivation and recurrent cancer due to use of immunosuppressants. Given these risks, it is undesirable for patients with advanced stage cervical cancer to undergo uterine transplantation. Thus, the disease stage should be determined and patients should undergo transplantation after confirmation of no recurrence for at least 5 years [95].

In Japan, uterine transplantation in humans is not approved, but data for non-human primates (cynomolgus monkeys) are currently being accumulated. Delivery after autotransplantation was achieved in 2013 and an experiment on uterine allotransplantation (assuming a brain-dead donor) is in progress. In cynomolgus monkeys, 
venous blood flow is maintained more easily in the deep uterine and ovarian veins than in the extremely narrow uterine veins, and surgery at the bottom of the pelvic floor is not required; therefore, use of the ovarian veins as pedicles in uterine transplantation is less invasive [96]. Uterine rejection can be avoided using specific immunosuppressive therapy, and the uterine graft gradually reduces and results in a scar without peritonitis or systemic infection. The uterus connection to outside the body through the vagina has a course that differs from the liver and kidney, which are intraabdominal and retroperitoneal organs [97]. This anatomical feature of the uterus may enable performance of biopsy for prompt diagnosis of rejection and adjustment to an appropriate dose of immunosuppressants. Safer procedures and immunosuppressant protocols are being developed in Japan, and transplantation of a human uterus is technically feasible. However, uterine transplantation is a transient organ graft that includes removal of the uterus after birth, and the uterus is not needed for life support. These characteristics differ from those in transplantation of other organs and raise ethical concerns. Guidelines are required that recognize the burdens and risks for recipients, donors and children, and infrastructure for a full support system is required.

\section{Conclusion}

In this article, fertility preservation in patients with malignant gynecological tumors and treatment of gynecological cancer in pregnant women are described. Fertility preservation may improve health and mental and social well-being in women, but may not be possible in treatment of some malignant gynecological tumors. Cryopreservation of unfertilized oocytes, embryos or ovarian tissue and uterine transplantation are promising approaches for patients who have undergone hysterectomy and oophorectomy, and advanced technology is likely to permit fertility preservation in all women.

\section{Acknowledgements}

We thank Dr. M. Ito and Dr. Y. Yano for helpful assistance. We gratefully acknowledge grant support from the Keio Gijuku Academic Development Fund. The funders had no role in data collection and analysis, decision to publish, or preparation of the manuscript.

\section{References}

[1] Loren, A.W., Mangu, P.B., Beck, L.N., Brennan, L., Magdalinski, A.J., Partridge, A.H., Quinn, G., Wallace, W.H. and Oktay, K. (2013) Fertility Preservation for Patients with Cancer: American Society of Clinical Oncology Clinical Practice Guideline Update. Journal of Clinical Oncology, 31, 2500-2510. http://dx.doi.org/10.1200/JCO.2013.49.2678

[2] Amant, F., Van Calsteren, K., Halaska, M.J., Beijnen, J., Lagae, L., Hanssens, M., Heyns, L., Lannoo, L., Ottevanger, N.P., Bogaert, W.V., Ungar, L., Vergote, I. and du Bois, A. (2009) Gynecologic Cancers in Pregnancy: Guidelines of an International Consensus Meeting. International Journal of Gynecological Cancer, 19, S1-S12. http://dx.doi.org/10.1111/IGC.0b013e3181a1d0ec

[3] Rieck, G. and Fiander, A. (2006) The Effect of Lifestyle Factors on Gynaecological Cancer. Best Practice \& Research Clinical Obstetrics \& Gynaecology, 20, 227-251. http://dx.doi.org/10.1016/j.bpobgyn.2005.10.010

[4] Miesfeldet, S., Lamb, A. and Duarte, C. (2013) Management of Genetic Syndromes Predisposing to Gynecologic Cancers. Current Treatment Options in Oncology, 14, 34-50. http://dx.doi.org/10.1007/s11864-012-0215-3

[5] Adachi, M., Banno, K., Yanokura, M., Iida, M., Nakamura, K., Nogami, Y., Umene, K., Masuda, K., Kisu, I., Ueki, A., Hirasawa, A., Tominaga, E. and Aoki, D. (2015) Risk-Reducing Surgery in Hereditary Gynecological Cancer: Clinical Applications in Lynch Syndrome and Hereditary Breast and Ovarian Cancer. Molecular and Clinical Oncology, 3, 267-273.

[6] Banno, K., Yanokura, M., Iida, M., Masuda, K. and Aoki, D. (2014) Carcinogenic Mechanisms of Endometrial Cancer: Involvement of Genetics and Epigenetics. Journal of Obstetrics and Gynaecology Research, 40, 1957-1967. http://dx.doi.org/10.1111/jog.12442

[7] National Comprehensive Cancer Network (NCCN) (2015) Clinical Practice Guidelines in Oncology. Genetic/Familial High-Risk Assessment: Breast and Ovarian. http://www.nccn.org/professionals/physician_gls/pdf/genetics_screening.pdf

[8] National Comprehensive Cancer Network (NCCN) (2015) Clinical Practice Guidelines in Oncology. Colorectal Cancer Screening. http://www.nccn.org/professionals/physician_gls/pdf/colorectal_screening.pdf

[9] Sadler, L., Saftlas, A., Wang, W., Exeter, M., Whittaker, J. and McCowan, L. (2004) Treatment for Cervical Intraepi- 
thelial Neoplasia and Risk of Preterm Delivery. JAMA, 291, 2100-2106. http://dx.doi.org/10.1001/jama.291.17.2100

[10] Kyrgiou, M., Koliopoulos, G., Martin-Hirsch, P., Arbyn, M., Prendiville, W. and Paraskevaidis, E. (2006) Obstetric Outcomes after Conservative Treatment for Intraepithelial or Early Invasive Cervical Lesions: Systematic Review and Meta-Analysis. Lancet, 367, 489-498. http://dx.doi.org/10.1016/S0140-6736(06)68181-6

[11] Bruinsma, F., Lumley, J., Tan, J. and Quinn, M. (2007) Precancerous Changes in the Cervix and Risk of Subsequent Preterm Birth. BJOG: An International Journal of Obstetrics \& Gynaecology, 114, 70-80. http://dx.doi.org/10.1111/j.1471-0528.2006.01107.x

[12] Arbyn, M., Kyrgiou, M., Simoens, C., Raifu, A.O., Koliopoulos, G., Martin-Hirsch, P., Prendiville, W. and Paraskevaidis, E. (2008) Perinatal Mortality and Other Severe Adverse Pregnancy Outcomes Associated with Treatment of Cervical Intraepithelial Neoplasia: Meta-Analysis. BMJ, 337, a1284. http://dx.doi.org/10.1136/bmj.a1284

[13] Noehr, B., Jensen, A., Frederiksen, K., Tabor, A. and Kjaer, S.K. (2009) Loop Electrosurgical Excision of the Cervix and Subsequent Risk for Spontaneous Preterm Delivery: A Population-Based Study of Singleton Deliveries during a 9-Year Period. American Journal of Obstetrics \& Gynecology, 201, 33.e1-33.e6. http://dx.doi.org/10.1016/j.ajog.2009.02.004

[14] Rob, L., Skapa, P. and Robova, H. (2011) Fertility-Sparing Surgery in Patients with Cervical Cancer. The Lancet Oncology, 12, 192-200. http://dx.doi.org/10.1016/S1470-2045(10)70084-X

[15] Plante, M. (2008) Vaginal Radical Trachelectomy: An Update. Gynecologic Oncology, 111, S105-S110. http://dx.doi.org/10.1016/j.ygyno.2008.07.020

[16] Ushijima, K., Yahata, H., Yoshikawa, H., Konishi, I., Yasugi, T., Saito, T., Nakanishi, T., Sasaki, H., Saji, F., Iwasaka, T., Hatae, M., Kodama, S., Saito, T., Terakawa, N., Yaegashi, N., Hiura, M., Sakamoto, A., Tsuda, H., Fukunaga, M. and Kamura, T. (2007) Multicenter Phase II Study of Fertility-Sparing Treatment with Medroxyprogesterone Acetate for Endometrial Carcinoma and Atypical Hyperplasia in Young Women. Journal of Clinical Oncology, 25, 2798-2803. http://dx.doi.org/10.1200/JCO.2006.08.8344

[17] Dhar, K.K., NeedhiRajan, T., Koslowski, M. and Woolas, R.P. (2005) Is Levonorgestrel Intrauterine System Effective for Treatment of Early Endometrial Cancer? Report of Four Cases and Review of the Literature. Gynecologic Oncology, 97, 924-927. http://dx.doi.org/10.1016/j.ygyno.2004.10.031

[18] Minig, L., Franchi, D., Boveri, S., Casadio, C., Bocciolone, L. and Sideri, M. (2011) Progestin Intrauterine Device and GnRH Analogue for Uterus-Sparing Treatment of Endometrial Precancers and Well-Differentiated Early Endometrial Carcinoma in Young Women. Annals of Oncology, 22, 643-649. http://dx.doi.org/10.1093/annonc/mdq463

[19] Kim, M.K. and Seong, S.J. (2014) Conservative Treatment for Atypical Endometrial Hyperplasia: What Is the Most Effective Therapeutic Method? Journal of Gynecologic Oncology, 25, 164-165. http://dx.doi.org/10.3802/jgo.2014.25.3.164

[20] Kaku, T., Yoshikawa, H., Tsuda, H., Sakamoto, A., Fukunaga, M., Kuwabara, Y., Hataeg, M., Kodama, S., Kuzuya, K., Sato, S., Nishimura, T., Hiura, M., Nakano, H., Iwasaka, T., Miyazaki, K. and Kamura, T. (2001) Conservative Therapy for Adenocarcinoma and Atypical Endometrial Hyperplasia of the Endometrium in Young Women: Central Pathologic Review and Treatment Outcome. Cancer Letters, 167, 39-48. http://dx.doi.org/10.1016/S0304-3835(01)00462-1

[21] Imai, M., Jobo, T., Sato, R., Kawaguchi, M. and Kuramoto, H. (2001) Medroxyprogesterone Acetate Therapy for Patients with Adenocarcinoma of the Endometrium Who Wish to Preserve the Uterus: Usefulness and Limitations. European Journal of Gynaecological Oncology, 22, 217-220.

[22] Utsunomiya, H., Suzuki, T., Ito, K., Moriya, T., Konno, R., Sato, S., Yaegashi, N., Okamura, K. and Sasano, H. (2003) The Correlation between the Response to Progestogen Treatment and the Expression of Progesterone Receptor B and $17 \beta$-Hydroxysteroid Dehydrogenase Type 2 in Human Endometrial Carcinoma. Clinical Endocrinology, 58, 696-703. http://dx.doi.org/10.1046/j.1365-2265.2003.01766.x

[23] Decruze, S.B. and Green, J.A. (2007) Hormone Therapy in Advanced and Recurrent Endometrial Cancer: A Systematic Review. International Journal of Gynecological Cancer, 17, 964-978. http://dx.doi.org/10.1111/j.1525-1438.2007.00897.x

[24] Zakikhani, M., Dowling, R., Fantus, I.G., Sonenberg, N. and Pollak, M. (2006) Metformin Is an AMP Kinase-Dependent Growth Inhibitor for Breast Cancer Cells. Cancer Research, 66, 10269-10273. http://dx.doi.org/10.1158/0008-5472.CAN-06-1500

[25] Dowling, R.J., Zakikhani, M., Fantus, I.G., Pollak, M. and Sonenberg, N. (2007) Metformin Inhibits Mammalian Target of Rapamycin-Dependent Translation Initiation in Breast Cancer Cells. Cancer Research, 67, 10804-10812. http://dx.doi.org/10.1158/0008-5472.CAN-07-2310

[26] Gotlieb, W.H., Saumet, J., Beauchamp, M.C., Gu, J., Lau, S., Pollak, M.N. and Bruchim, I. (2008) In Vitro Metformin Anti-Neoplastic Activity in Epithelial Ovarian Cancer. Gynecologic Oncology, 110, 246-250.

http://dx.doi.org/10.1016/j.ygyno.2008.04.008 
[27] Wang, L.W., Li, Z.S., Zou, D.W., Jin, Z.D., Gao, J. and Xu, G.M. (2008) Metformin Induces Apoptosis of Pancreatic Cancer Cells. World Journal of Gastroenterology, 14, 7192-7198. http://dx.doi.org/10.3748/wjg.14.7192

[28] Ben Sahra, I., Laurent, K., Loubat, A., Giorgetti-Peraldi, S., Colosetti, P., Auberger, P., Tanti, J.F., Le MarchandBrustel, Y. and Bost, F. (2008) The Antidiabetic Drug Metformin Exerts an Antitumoral Effect in Vitro and in Vivo through a Decrease of Cyclin D1 Level. Oncogene, 27, 3576-3586. http://dx.doi.org/10.1038/sj.onc.1211024

[29] Cantrell, L.A., Zhou, C., Mendivil, A., Malloy, K.M., Gehrig, P.A. and Bae-Jump, V.L. (2010) Metformin Is a Potent Inhibitor of Endometrial Cancer Cell Proliferation: Implications for a Novel Treatment Strategy. Gynecologic Oncology, 116, 92-98. http://dx.doi.org/10.1016/j.ygyno.2009.09.024

[30] Ko, E.M., Walter, P., Jackson, A., Clark, L., Franasiak, J., Bolac, C., Havrilesky, L.J., Secord, A.A., Moore, D.T., Gehrig, P.A. and Bae-Jump, V. (2014) Metformin Is Associated with Improved Survival in Endometrial Cancer. Gynecologic Oncology, 132, 438-442. http://dx.doi.org/10.1016/j.ygyno.2013.11.021

[31] Nevadunsky, N.S., Van Arsdale, A., Strickler, H.D., Moadel, A., Kaur, G., Frimer, M., Conroy, E., Goldberg, G.L. and Einstein, M.H. (2014) Metformin Use and Endometrial Cancer Survival. Gynecologic Oncology, 132, 236-240. http://dx.doi.org/10.1016/j.ygyno.2013.10.026

[32] Jobo, T., Yonaha, H., Iwaya, H., Kanai, T. and Kuramoto, H. (2000) Conservative Surgery for Malignant Ovarian Tumor in Women of Childbearing Age. International Journal of Clinical Oncology, 5, 41-47. http://dx.doi.org/10.1007/s101470050008

[33] Zanetta, G., Rota, S., Chiari, S., Bonazzi, C., Bratina, G. and Mangioni, C. (2001) Behavior of Borderline Tumors with Particular Interest to Persistence, Recurrence, and Progression to Invasive Carcinoma: A Prospective Study. Journal of Clinical Oncology, 19, 2658-2664.

[34] Li, J., Yang, W. and Wu, X. (2007) Prognostic Factors and Role of Salvage Surgery in Chemorefractory Ovarian Germ Cell Malignancies: A Study in Chinese Patients. Gynecologic Oncology, 105, 769-775. http://dx.doi.org/10.1016/j.ygyno.2007.02.032

[35] Bajorin, D.F., Sarosdy, M.F., Pfister, D.G., Mazumdar, M., Motzer, R.J., Scher, H.I., Geller, N.L., Fair, W.R., Herr, H. and Sogani, P. (1993) Randomized Trial of Etoposide and Cisplatin versus Etoposide and Carboplatin in Patients with Good-Risk Germ Cell Tumors: A Multiinstitutional Study. Journal of Clinical Oncology, 11, 598-606.

[36] Satoh, T., Hatae, M., Watanabe, Y., Yaegashi, N., Ishiko, O., Kodama, S., Yamaguchi, S., Ochiai, K., Takano, M., Yokota, H., Kawakami, Y., Nishimura, S., Ogishima, D., Nakagawa, S., Kobayashi, H., Shiozawa, T., Nakanishi, T., Kamura, T., Konishi, I. and Yoshikawa, H. (2010) Outcomes of Fertility-Sparing Surgery for Stage I Epithelial Ovarian Cancer: A Proposal for Patient Selection. Journal of Clinical Oncology, 28, 1727-1732. http://dx.doi.org/10.1200/JCO.2009.24.8617

[37] Trillsch, F., Mahner, S., Woelber, L., Vettorazzi, E., Reuss, A., Ewald-Riegler, N., de Gregorio, N., Fotopoulou, C., Schmalfeldt, B., Burges, A., Hilpert, F., Fehm, T., Meier, W., Hillemanns, P., Hanker, L., Hasenburg, A., Strauss, H.G., Hellriegel, M., Wimberger, P., Baumann, K., Keyver-Paik, M.D., Canzler, U., Wollschlaeger, K., Forner, D., Pfisterer, J., Schroeder, W., Muenstedt, K., Richter, B., Kommoss, F., Hauptmann, S. and du Bois, A. (2014) Age-Dependent Differences in Borderline Ovarian Tumours (BOT) Regarding Clinical Characteristics and Outcome: Results from a Sub-Analysis of the Arbeitsgemeinschaft Gynaekologische Onkologie (AGO) ROBOT Study. Annals of Oncology, 25, 1320-1327. http://dx.doi.org/10.1093/annonc/mdu119

[38] Uzan, C., Kane, A., Rey, A., Gouy, S., Duvillard, P. and Morice, P. (2010) Outcomes after Conservative Treatment of Advanced-Stage Serous Borderline Tumors of the Ovary. Annals of Oncology, 21, 55-60. http://dx.doi.org/10.1093/annonc/mdp267

[39] Mangili, G., Sigismondi, C., Gadducci, A., Cormio, G., Scollo, P., Tateo, S., Ferrandina, G., Greggi, S., Candiani, M. and Lorusso, D. (2011) Outcome and Risk Factors for Recurrence in Malignant Ovarian Germ Cell Tumors: A MITO-9 Retrospective Study. International Journal of Gynecological Cancer, 21, 1414-1421. http://dx.doi.org/10.1097/IGC.0b013e3182236582

[40] Pavlidis, N.A. (2002) Coexistence of Pregnancy and Malignancy. Oncologist, 7, 279-287. http://dx.doi.org/10.1634/theoncologist.7-6-573

[41] Kal, H.B. and Struikmans, H. (2005) Radiotherapy during Pregnancy: Fact and Fiction. The Lancet Oncology, 6, 328333. http://dx.doi.org/10.1016/S1470-2045(05)70169-8

[42] Hertel, H., Possover, M., Kühne-Heid, R. and Schneider, A. (2001) Laparoscopic Lymph Node Staging of Cervical Cancer in the 19th Week of Pregnancy. A Case Report. Surgical Endoscopy, 15, 324. http://dx.doi.org/10.1007/s004640042005

[43] Alouini, S., Rida, K. and Mathevet, P. (2008) Cervical Cancer Complicating Pregnancy: Implications of Laparoscopic Lymphadenectomy. Gynecologic Oncology, 108, 472-477. http://dx.doi.org/10.1016/j.ygyno.2007.12.006

[44] Covell, L.M., Disciullo, A.J. and Knapp, R.C. (1977) Decidual Change in Pelvic Lymph Nodes in the Presence of Cervical Squamous Cell Carcinoma during Pregnancy. American Journal of Obstetrics \& Gynecology, 127, 674-676. 
[45] Schmeler, K.M., Frumovitz, M. and Ramirez, P.T. (2011) Conservative Management of Early Stage Cervical Cancer: Is There a Role for Less Radical Surgery? Gynecologic Oncology, 120, 321-325. http://dx.doi.org/10.1016/j.ygyno.2010.12.352

[46] Morice, P., Uzan, C., Gouy, S., Verschraegen, C. and Haie-Meder, C. (2012) Gynaecological Cancers in Pregnancy. Lancet, 379, 558-569. http://dx.doi.org/10.1016/S0140-6736(11)60829-5

[47] Ungár, L., Smith, J.R., Pálfalvi, L. and Del Priore, G. (2006) Abdominal Radical Trachelectomy during Pregnancy to Preserve Pregnancy and Fertility. Obstetrics \& Gynecology, 108, 811-814. http://dx.doi.org/10.1097/01.AOG.0000216015.15415.5f

[48] Iwami, N., Ishioka, S., Endo, T., Baba, T., Nagasawa, K., Takahashi, M., Sugio, A., Takada, S., Mariya, T., Mizunuma, M. and Saito, T. (2011) First Case of Vaginal Radical Trachelectomy in a Pregnant Japanese Woman. International Journal of Clinical Oncology, 16, 737-740. http://dx.doi.org/10.1007/s10147-011-0209-3

[49] Aoki, Y., Inamine, M., Ohishi, S., Nagai, Y. and Masamoto, H. (2014) Radical Abdominal Trachelectomy for IB1 Cervical Cancer at 17 Weeks of Gestation: A Case Report and Literature Review. Case Reports in Obstetrics and Gynecology, 2014, Article ID: 926502. http://dx.doi.org/10.1155/2014/926502

[50] Rydzewska, L., Tierney, J., Vale, C.L. and Symonds, P.R. (2012) Neoadjuvant Chemotherapy plus Surgery versus Surgery for Cervical Cancer. Cochrane Database of Systematic Reviews, No. 12, Article No.: CD007406. http://dx.doi.org/10.1002/14651858.cd007406.pub3

[51] Amant, F., Halaska, M.J., Fumagalli, M., Dahl Steffensen, K., Lok, C., Van Calsteren, K., Han, S.N., Mir, O., Fruscio, R., Uzan, C., Maxwell, C., Dekrem, J., Strauven, G., Mhallem Gziri, M., Kesic, V., Berveiller, P., van den Heuvel, F., Ottevanger, P.B., Vergote, I., Lishner, M., Morice, P. and Nulman, I. (2014) Gynecologic Cancers in Pregnancy: Guidelines of a Second International Consensus Meeting. International Journal of Gynecological Cancer, 24, 394-403. http://dx.doi.org/10.1097/IGC.0000000000000062

[52] Zagouri, F., Sergentanis, T.N., Chrysikos, D. and Bartsch, R. (2013) Platinum Derivatives during Pregnancy in Cervical Cancer: A Systematic Review and Meta-Analysis. Obstetrics \& Gynecology, 121, 337-343.

[53] Van Calsteren, K., Verbesselt, R., Ottevanger, N., Halaska, M., Heyns, L., Van Bree, R., de Bruijn, E., Chai, D., Delforge, M., Noens, L., Renard, V., Witteveen, E., Rob, L., de Hoon, J. and Amant, F. (2010) Pharmacokinetics of Chemotherapeutic Agents in Pregnancy: A Preclinical and Clinical Study. Acta Obstetricia et Gynecologica Scandinavica, 89, 1338-1345. http://dx.doi.org/10.3109/00016349.2010.512070

[54] Amant, F., von Minckwitz, G., Han, S.N., Bontenbal, M., Ring, A.E., Giermek, J., Wildiers, H., Fehm, T., Linn, S.C., Schlehe, B., Neven, P., Westenend, P.J., Muller, V., Van Calsteren, K., Rack, B., Nekljudova, V., Harbeck, N., Untch, M., Witteeen, P.O., Schwedler, K., Thomssen, C., Van Calster, B. and Loibi, S. (2013) Prognosis of Women with Primary Breast Cancer Diagnosed during Pregnancy: Results from an International Collaborative Study. Journal of Clinical Oncology, 31, 2532-2539. http://dx.doi.org/10.1200/JCO.2012.45.6335

[55] Hoover, K. and Jenkins, T.R. (2011) Evaluation and Management of Adnexal Mass in Pregnancy. American Journal of Obstetrics \& Gynecology, 205, 97-102. http://dx.doi.org/10.1016/j.ajog.2011.01.050

[56] Leiserowitz, G.S. (2006) Managing Ovarian Masses during Pregnancy. Obstetrical \& Gynecological Survey, 61, 463470. http://dx.doi.org/10.1097/01.ogx.0000224614.51356.b7

[57] Aggarwal, P. and Kehoe, S. (2011) Ovarian Tumours in Pregnancy: A Literature Review. European Journal of Obstetrics \& Gynecology and Reproductive Biology, 155, 119-124. http://dx.doi.org/10.1016/j.ejogrb.2010.11.023

[58] Mathevet, P., Nessah, K., Darget, D. and Mellier, G. (2003) Laparoscopic Management of Adnexal Masses in Pregnancy: A Case Series. European Journal of Obstetrics \& Gynecology and Reproductive Biology, 108, 217-222. http://dx.doi.org/10.1016/s0301-2115(02)00374-3

[59] Mir, O., Berveiller, P., Ropert, S., Goffinet, F., Pons, G., Treluyer, J.M. and Goldwasser, F. (2008) Emerging Therapeutic Options for Breast Cancer Chemotherapy during Pregnancy. Annals of Oncology, 19, 607-613. http://dx.doi.org/10.1093/annonc/mdm460

[60] Van Calsteren, K., Heyns, L., De Smet, F., Van Eycken, L., Gziri, M.M., Van Gemert, W., Halaska, M., Vergote, I., Ottevanger, N. and Amant, F. (2010) Cancer during Pregnancy: An Analysis of 215 Patients Emphasizing the Obstetrical and the Neonatal Outcomes. Journal of Clinical Oncology, 28, 683-689. http://dx.doi.org/10.1200/JCO.2009.23.2801

[61] Cardonick, E. and Iacobucci, A. (2004) Use of Chemotherapy during Human Pregnancy. The Lancet Oncology, 5, 283291. http://dx.doi.org/10.1016/S1470-2045(04)01466-4

[62] Amant, F., Van Calsteren, K., Halaska, M.J., Gziri, M.M., Hui, W., Lagae, L., Willemsen, M.A., Kapusta, L., Van Calster, B., Wouters, H., Heyns, L., Han, S.N., Tomek, V., Mertens, L. and Ottevanger, P.B. (2012) Long-Term Cognitive and Cardiac Outcomes after Prenatal Exposure to Chemotherapy in Children Aged 18 Months or Older: An Observational Study. The Lancet Oncology, 13, 256-264. http://dx.doi.org/10.1016/S1470-2045(11)70363-1 
[63] Gziri, M.M., Debiève, F., DECatte, L., Mertens, L., Barrea, C., van Calsteren, K., Han, S.N., Heyns, L. and Amant, F. (2012) Chemotherapy during Pregnancy: Effect of Anthracyclines on Fetal and Maternal Cardiac Function. Acta Obstetricia et Gynecologica Scandinavica, 91, 1465-1468. http://dx.doi.org/10.1111/j.1600-0412.2012.01524.X

[64] Gurumurthy, M., Koh, P., Singh, R., Bhide, A., Satodia, P., Hocking, M., Anbarasu, A. and Wood, L.E. (2009) Metastatic Non-Small-Cell Lung Cancer and the Use of Gemcitabine during Pregnancy. Journal of Perinatology, 29, 63-65. http://dx.doi.org/10.1038/jp.2008.128

[65] Prat, J. (2015) FIGO’s Staging Classification for Cancer of the Ovary, Fallopian Tube, and Peritoneum: Abridged Republication. Journal of Gynecologic Oncology, 26, 87-89. http://dx.doi.org/10.3802/jgo.2015.26.2.87

[66] Chen, C.H., Chiu, L.H., Chan, C. and Liu, W.M. (2015) Management of Ovarian Cancer in 14th Gestational Week of Pregnancy by Robotic Approach with Preservation of the Fetus. Gynecologic and Obstetric Investigation, 80, 139-144. http://dx.doi.org/10.1159/000368231

[67] Machado, F., Vegas, C., Leon, J., Perez, A., Sanchez, R., Parrilla, J.J. and Abad, L. (2007) Ovarian Cancer during Pregnancy: Analysis of 15 Cases. Gynecologic Oncology, 105, 446-450. http://dx.doi.org/10.1016/j.ygyno.2007.01.002

[68] Tewari, K., Brewer, C., Cappuccini, F., Macri, C., Rogers, L.W. and Berman, M.L. (1997) Advanced-Stage Small Cell Carcinoma of the Ovary in Pregnancy: Long-Term Survival after Surgical Debulking and Multiagent Chemotherapy. Gynecologic Oncology, 66, 531-534. http://dx.doi.org/10.1006/gyno.1997.4801

[69] Mancari, R., Tomasi-Cont, N., Sarno, M.A., Azim Jr., H.A., Franchi, D., Carinelli, S., Biglia, N., Colombo, N. and Peccatori, F.A. (2014) Treatment Options for Pregnant Women with Ovarian Tumors. International Journal of Gynecological Cancer, 24, 967-972. http://dx.doi.org/10.1097/IGC.0000000000000161

[70] Zagouri, F., Sergentanis, T.N., Chrysikos, D., Filipits, M. and Bartsch, R. (2012) Taxanes for Ovarian Cancer during Pregnancy: A Systematic Review. Oncology, 83, 234-238. http://dx.doi.org/10.1159/000341351

[71] Lambertini, M., Peccatori, F.A. and Azim Jr., H.A. (2014) Targeted Agents for Cancer Treatment during Pregnancy. Cancer Treatment Reviews, 41, 301-309. http://dx.doi.org/10.1016/j.ctrv.2015.03.001

[72] Sood, A.K., Shahin, M.S. and Sorosky, J.I. (2001) Paclitaxel and Platinum Chemotherapy for Ovarian Carcinoma during Pregnancy. Gynecologic Oncology, 83, 599-600. http://dx.doi.org/10.1006/gyno.2001.6439

[73] Motegi, M., Takakura, S., Takano, H., Tanaka, T. and Ochiai, K. (2007) Adjuvant Chemotherapy in a Pregnant Woman with Endodermal Sinus Tumor of the Ovary. Obstetrics \& Gynecology, 109, 537-540. http://dx.doi.org/10.1097/01.AOG.0000245450.62758.47

[74] Ataya, K., Rao, L.V., Lawrence, E. and Kimmel, R. (1995) Luteinizing Hormone-Releasing Hormone Agonist Inhibits Cyclophosphamide-Induced Ovarian Follicular Depletion in Rhesus Monkeys. Biology of Reproduction, 52, 365-372. http://dx.doi.org/10.1095/biolreprod52.2.365

[75] Blumenfeld, Z. (2001) Ovarian Rescue/Protection from Chemotherapeutic Agents. Journal of the Society for Gynecologic Investigation, 8, S60-S64. http://dx.doi.org/10.1016/S1071-5576(00)00112-X

[76] Beck-Fruchter, R., Weiss, A. and Shalev, E. (2008) GnRH Agonist Therapy as Ovarian Protectants in Female Patients Undergoing Chemotherapy: A Review of the Clinical Data. Human Reproduction Update, 14, 553-561.

http://dx.doi.org/10.1093/humupd/dmn041

[77] Munster, P.N., Moore, A.P., Ismail-Khan, R., Cox, C.E., Lacevic, M., Gross-King, M., Xu, P., Carter, W.B. and Minton, S.E. (2012) Randomized Trial Using Gonadotropin-Releasing Hormone Agonist Triptorelin for the Preservation of Ovarian Function during (Neo) Adjuvant Chemotherapy for Breast Cancer. Journal of Clinical Oncology, 10, 533-538. http://dx.doi.org/10.1200/JCO.2011.34.6890

[78] Chen, H., Wang, Y., Lyu, Q., Ai, A., Fu, Y., Tian, H., Cai, R., Hong, Q., Chen, Q., Shoham, Z. and Kuang, Y. (2015) Comparison of Live-Birth Defects after Luteal-Phase Ovarian Stimulation vs. Conventional Ovarian Stimulation for in Vitro Fertilization and Vitrified Embryo Transfer Cycles. Fertility and Sterility, 103, 1194-1201. http://dx.doi.org/10.1016/j.fertnstert.2015.02.020

[79] Dolmans, M.M., Demylle, D., Martinez-Madrid, B. and Donnez, J. (2005) Efficacy of in Vitro Fertilization after Chemotherapy. Fertility and Sterility, 83, 897-901. http://dx.doi.org/10.1016/j.fertnstert.2004.08.035

[80] Goldman, K.N., Noyes, N.L., Knopman, J.M., McCaffrey, C. and Grifo, J.A. (2013) Oocyte Efficiency: Does Live Birth Rate Differ When Analyzing Cryopreserved and Fresh Oocytes on a Per-Oocyte Basis? Fertility and Sterility, 100, 712-717. http://dx.doi.org/10.1016/j.fertnstert.2013.04.040

[81] Oktay, K. and Karlikaya, G. (2000) Ovarian Function after Transplantation of Frozen, Banked Autologous Ovarian Tissue. The New England Journal of Medicine, 342, 1919. http://dx.doi.org/10.1056/NEJM200006223422516

[82] Donnez, J., Dolmans, M.M., Demylle, D., Jadoul, P., Pirard, C., Squifflet, J., Martinez-Madrid, B. and van Langendonckt, A. (2004) Livebirth after Orthotopic Transplantation of Cryopreserved Ovarian Tissue. Lancet, 364, 1405-1410. http://dx.doi.org/10.1016/S0140-6736(04)17222-X 
[83] Demeestere, I., Simon, P., Dedeken, L., Moffa, F., Tsépélidis, S., Brachet, C., Delbaere, A., Devreker, F. and Ferster, A. (2015) Live Birth after Autograft of Ovarian Tissue Cryopreserved during Childhood. Human Reproduction, 30, 2107-2109. http://dx.doi.org/10.1093/humrep/dev128

[84] Dolmans, M.M., Luyckx, V., Donnez, J., Anderson, C.Y. and Greve, T. (2013) Risk of Transferring Malignant Cells with Transplanted Frozen-Thawed Ovarian Tissue. Fertility and Sterility, 99, 1514-1522. http://dx.doi.org/10.1016/j.fertnstert.2013.03.027

[85] Chan, P.G., Sung, H.Y. and Sawaya, G.F. (2003) Changes in Cervical Cancer Incidence after Three Decades of Screening US Women Less than 30 Years Old. Obstetrics \& Gynecology, 102, 765-773. http://dx.doi.org/10.1016/S0029-7844(03)00696-3

[86] Touhami, O. and Plante, M. (2015) Should Ovaries Be Removed or Not in (Early-Stage) Adenocarcinoma of the Uterine Cervix: A Review. Gynecologic Oncology, 136, 384-388. http://dx.doi.org/10.1016/j.ygyno.2014.12.011

[87] Bastings, L., Beerendonk, C.C., Westphal, J.R., Massuger, L.F., Kaal, S.E., van Leeuwen, F.E., Braat, D.D. and Peek, R. (2013) Autotransplantation of Cryopreserved Ovarian Tissue in Cancer Survivors and the Risk of Reintroducing Malignancy: A Systematic Review. Human Reproduction Update, 19, 483-506. http://dx.doi.org/10.1093/humupd/dmt020

[88] Tomao, F., Peccatori, F., Pup, L.D., Franchi, D., Zanagnolo, V., Panici, P.B. and Colombo, N. (2015) Special Issues in Fertility Preservation for Gynecologic Malignancies. Critical Reviews in Oncology/Hematology, Epub ahead of print.

[89] Fageeh, W., Raffa, H., Jabbad, H. and Marzouki, A. (2002) Transplantation of the Human Uterus. International Journal of Gynecology \& Obstetrics, 76, 245-251. http://dx.doi.org/10.1016/s0020-7292(01)00597-5

[90] Erman Akar, M., Ozkan, O., Aydinuraz, B., Dirican, K., Cincik, M., Mendilcioglu, I., Simsek, M., Gunseren, F., Kocak, H., Ciftcioglu, A., Gecici, O. and Ozkan, O. (2013) Clinical Pregnancy after Uterus Transplantation. Fertility and Sterility, 100, 1358-1363. http://dx.doi.org/10.1016/j.fertnstert.2013.06.027

[91] Brännström, M., Johannesson, L., Bokström, H., Kvarnström, N., Mölne, J., Dahm-Kähler, P., Enskog, A., Milenkovic, M., Ekberg, J., Diaz-Garcia, C., Gäbel, M., Hanafy, A., Hagberg, H., Olausson, M. and Nilsson, L. (2015) Live Birth after Uterus Transplantation. Lancet, 385, 607-616. http://dx.doi.org/10.1016/S0140-6736(14)61728-1

[92] Brännström, M., Johannesson, L., Dahm-Kähler, P., Enskog, A., Mölne, J., Kvarnström, N., Diaz-Garcia, C., Hanafy, A., Lundmark, C., Marcickiewicz, J., Gäbel, M., Groth, K., Akouri, R., Eklind, S., Holgersson, J., Tzakis, A. and Olausson, M. (2014) First Clinical Uterus Transplantation Trial: A Six-Month Report. Fertility and Sterility, 101, 1228-1236. http://dx.doi.org/10.1016/j.fertnstert.2014.02.024

[93] Vajdic, C.M., McDonald, S.P., McCredie, M.R., van Leeuwen, M.T., Stewart, J.H., Law, M., Chapman, J.R., Webster, A.C., Kaldor, J.M. and Grulich, A.E. (2006) Cancer Incidence before and after Kidney Transplantation. JAMA, 296, 2823-2831. http://dx.doi.org/10.1001/jama.296.23.2823

[94] Ozsaran, A.A., Ateş, T., Dikmen, Y., Zeytinoglu, A., Terek, C., Erhan, Y., Ozacar, T. and Bilgiç, A. (1999) Evaluation of the Risk of Cervical Intraepithelial Neoplasia and Human Papilloma Virus Infection in Renal Transplant Patients Receiving Immunosuppressive Therapy. European Journal of Gynaecological Oncology, 20, 127-130.

[95] Kisu, I., Banno, K., Mihara, M., Suganuma, N. and Aoki, D. (2013) Current Status of Uterus Transplantation in Primates and Issues for Clinical Application. Fertility and Sterility, 100, 280-294. http://dx.doi.org/10.1016/j.fertnstert.2013.03.004

[96] Kisu, I., Banno, K., Mihara, M., Hara, H., Umene, K., Adachi, M., Nogami, Y. and Aoki, D. (2015) A Surgical Technique Using the Ovarian Vein in Non-Human Primate Models of Potential Living-Donor Surgery of Uterus Transplantation. Acta Obstetricia et Gynecologica Scandinavica, 94, 942-948. http://dx.doi.org/10.1111/aogs.12701

[97] Kisu, I., Mihara, M., Banno, K., Hara, H., Masugi, Y., Araki, J., Iida, T., Yamada, Y., Kato, Y., Shiina, T., Suganuma, N. and Aoki, D. (2014) Uterus Allotransplantation in Cynomolgus Macaque: A Preliminary Experience with NonHuman Primate Models. Journal of Obstetrics and Gynaecology Research, 40, 907-918.

http://dx.doi.org/10.1111/jog.12302 


\section{Abbreviations List}

ASCO: American Society of Clinical Oncology

HPV: human papillomavirus

HBOC: hereditary breast and ovarian cancer

BRCA: breast cancer susceptibility gene

MMR: mismatch repair

MLH1: mutL homolog 1

MSH2: mutS homolog 2

MSH6: mutS homolog 6

PMS2: postmeiotic segregation increased 2

LEEP: loop electrosurgical excision procedure

VRT: vaginal radical trachelectomy

ART: abdominal radical trachelectomy

MPA: medroxyprogesterone acetate

AMPK: AMP-activated protein kinase

mTOR: mammalian target of rapamycin

S6K: S6 kinase

NACT: neoadjuvant chemotherapy

BEP: bleomycin, etoposide and cisplatin

GnRH: gonadotropin-releasing hormone

LBR-MOR: live birth rate per mature oocyte retrieved

MMF: mycophenolate mofetil 